\title{
Assessment of Vitamin D Levels and Its Correlation With Osteoporosis and Fracture Site Comminution in Osteoporotic Hip Fractures in Tertiary Care Hospital
}

\author{
Kishore Vellingiri ${ }^{1}$, Prabhu Ethiraj ${ }^{1}$, Nagakumar J. S. ${ }^{1}$, Arun H. Shanthappa ${ }^{1}$, Karthik S. J. ${ }^{1}$ \\ 1. Department of Orthopaedics, Sri Devaraj Urs Medical College, Sri Devaraj Urs Academy of Higher Education and \\ Research, Kolar, IND
}

Corresponding author: Prabhu Ethiraj, prabhu.thepreacher@gmail.com

Review began 01/14/2021 Review ended 01/25/2021 Published 01/29/2021

\section{() Copyright 2021}

Vellingiri et al. This is an open access article distributed under the terms of the Creative Commons Attribution License CC-BY 4.0., which permits unrestricted use, distribution, and reproduction in any medium, provided the original author and source are credited.

\begin{abstract}
Introduction: A global concern is vitamin D deficiency and insufficiency. There is a particularly high risk for pregnant women, people of color (Blacks, Hispanics, and those with increased skin melanin pigmentation), obese children and adults, and children and adults who are abstinent from direct sun exposure. The goal of this study was to understand the incidence of vitamin D deficiency in patients with osteoporotic hip fractures in our rural population and also to know its association with osteoporosis and osteoporotic hip fractures in a tertiary care trauma center.

Methods: This prospective research was performed at our tertiary trauma treatment center in Kolar, Karnataka, India by the Department of Orthopedics from September 2019 and July 2020. The age category was 45-90 years, intertrochanteric fractures were graded using the Boyd and Griffin classification and femoral neck fractures the Garden's staging. The research included all patients with fractures after a trivial trauma such as slip and fall while standing/walking and excluded patients with a serious history of trauma such as road traffic accidents/falls from height and pathological fractures. This study involved 30 patients. Age and gender, type of fracture, vitamin D levels, Singh's index, and comminution of fracture site were reported in patient demographics.
\end{abstract}

Results: Thirty patients comprised the study population. Most of them were female. Females comprised 18 out of the 30. There were twelve, thirteen, and five persons in our sample population between the ages of $45-60,61-75$, and $>75$ years. The Singh's index was tabulated. Mean vitamin D levels were $9.64+/-3.23$ in the femur fracture group and $13.42+/-5.31$ in the intertrochanteric fracture group. Mean levels of vitamin D are included as a graphical representation. The comminution of the fracture site in groups of the femur and intertrochanteric fractures was eight and six, respectively.

Conclusion: Early diagnosis and treatment of these patients with vitamin D for osteomalacia and antiosteoporotic osteoporosis regimens will hopefully enhance bone, muscle, and general health, minimizing falls and fractures.

Categories: Orthopedics, Trauma

Keywords: vitamin-d deficiency, osteoporotic hip fractures

\section{Introduction}

Global concern is vitamin D deficiency and insufficiency [1]. There is a particularly high risk for pregnant women, people of color (Blacks, Hispanics, and those with increased skin melanin pigmentation), obese children and adults, and children and adults who are abstinent from direct sun exposure [2]. Using the Chemiluminescence Immuno Assay, serum levels of 25-hydroxyvitamin D (25-OH vitamin D) were analyzed in the laboratory using an automated analyzer. Vitamin D less than $20 \mathrm{ng} / \mathrm{ml}$ serum level was considered to be deficient. Vitamin D level was considered to be inadequate between 20 and $29 \mathrm{ng} / \mathrm{ml}$ called vitamin D deficiency (hypovitaminosis D) and Vitamin D levels were considered normal between 30 and $100 \mathrm{ng} / \mathrm{ml}$ [3]. Evidence-based screening methods can increase the detection of patients who are most likely to benefit from fracture prevention drug treatment. Furthermore, thorough consideration of when to start pharmacotherapy and the option of medication and treatment period can optimize the benefits of fracture prevention while minimizing the possible harms of long-term drug exposure [4]. The goal of this study was to understand the incidence of vitamin D deficiency in patients with osteoporotic hip fracture in our rural population and also to know its association with osteoporosis and osteoporotic hip fractures in a tertiary care trauma center.

This research was accepted at the 8th International Conference on Health and Medicine, 30 January 2021, in Colombo, Sri Lanka, for a virtual presentation. The abstract of this article will be published in the conference online supplement. 


\section{Cureus}

\section{Materials And Methods}

This prospective research was performed at our tertiary trauma treatment center in Kolar, Karnataka, India by the Department of Orthopedics from September 2019 and July 2020. The institutional ethics committee approved this study. The age category was $45-90$ years. Intertrochanteric fractures were graded using the Boyd and Griffin classification and femoral neck fractures the Garden's staging. The research included all patients with fractures after a trivial trauma such as slip and fall while standing/walking and excluded patients with a serious history of trauma such as road traffic accidents/falls from height and pathological fractures. This study involved 30 patients. Age and gender, type of fracture, vitamin D levels, Singh's index, and comminution of fracture site were reported in patient demographics. The information collected was coded and entered into an Excel file. The mean and standard deviation were calculated. To determine the statistical significance, the t-test was used for continuous variables and the Chi-square test for categorical variables. A p-value $<0.05$ was considered statistically significant.

\section{Results}

Thirty patients comprised the study population. Most of them were females. Females comprised 18 out of the 30 . There were twelve, thirteen, and five persons in our sample population between the ages of 45-60, 61-75, and $>75$ years (Table 1). The Singh's index is shown in Table 2. Mean vitamin D levels were 9.64+/3.23 in the femur neck fracture group and $13.42+/-5.31$ in the intertrochanteric fracture group, given in Table 3. Mean levels of vitamin D are shown in Figure 1. The comminution of the fracture site in groups of the femur and intertrochanteric fractures was eight and six, respectively.

\begin{tabular}{|c|c|c|c|c|}
\hline \multirow{2}{*}{ Age in years } & \multicolumn{2}{|l|}{ Fracture type } & \multirow{2}{*}{ Total } & \multirow{2}{*}{ p-Value } \\
\hline & Femur neck & IT & & \\
\hline $45-60$ & 3 & 9 & 12 & \multirow{4}{*}{0.540} \\
\hline $61-75$ & 6 & 7 & 13 & \\
\hline$>75$ & 2 & 3 & 5 & \\
\hline Total & 11 & 19 & 30 & \\
\hline
\end{tabular}

\section{TABLE 1: Age and fracture type between groups}

IT: intertrochanteric.

\begin{tabular}{|c|c|c|c|c|c|}
\hline \multirow{2}{*}{ Singh index } & \multicolumn{2}{|c|}{ Fracture type } & \multirow{2}{*}{ Total } & \multirow{2}{*}{ Chi-square } & \multirow{2}{*}{ p-Value } \\
\hline & Femur neck & IT & & & \\
\hline 1 & 3 & 4 & 7 & \multirow{5}{*}{5.706} & \multirow{5}{*}{0.127} \\
\hline 2 & 3 & 2 & 5 & & \\
\hline 3 & 5 & 6 & 11 & & \\
\hline 4 & 0 & 7 & 7 & & \\
\hline Total & 11 & 19 & 30 & & \\
\hline
\end{tabular}

\section{TABLE 2: Singh's index between groups}

$\mathrm{IT}$ intertrochanteric. 


\section{Cureus}

\begin{tabular}{|c|c|c|c|c|c|}
\hline \multirow{3}{*}{ Vitamin D levels } & Fracture type & $\mathbf{N}$ & Mean & Standard deviation & p-Value \\
\hline & Femur neck & 11 & 9.64 & 3.233 & \multirow{2}{*}{0.022} \\
\hline & IT & 19 & 13.42 & 5.316 & \\
\hline
\end{tabular}

\section{TABLE 3: Vitamin D levels between groups}

$\mathrm{IT}$ : intertrochanteric.

\begin{tabular}{|c|c|c|c|c|}
\hline \multirow{2}{*}{ Fracture site comminution } & \multicolumn{2}{|l|}{ Fracture type } & \multirow{2}{*}{ Total } & \multirow{2}{*}{ p-Value } \\
\hline & Femur neck & IT & & \\
\hline No & 3 & 13 & 16 & \multirow{3}{*}{0.029} \\
\hline Yes & 8 & 6 & 14 & \\
\hline Total & 11 & 19 & 30 & \\
\hline
\end{tabular}

TABLE 4: Fracture site comminution and fracture type between groups

IT: intertrochanteric.

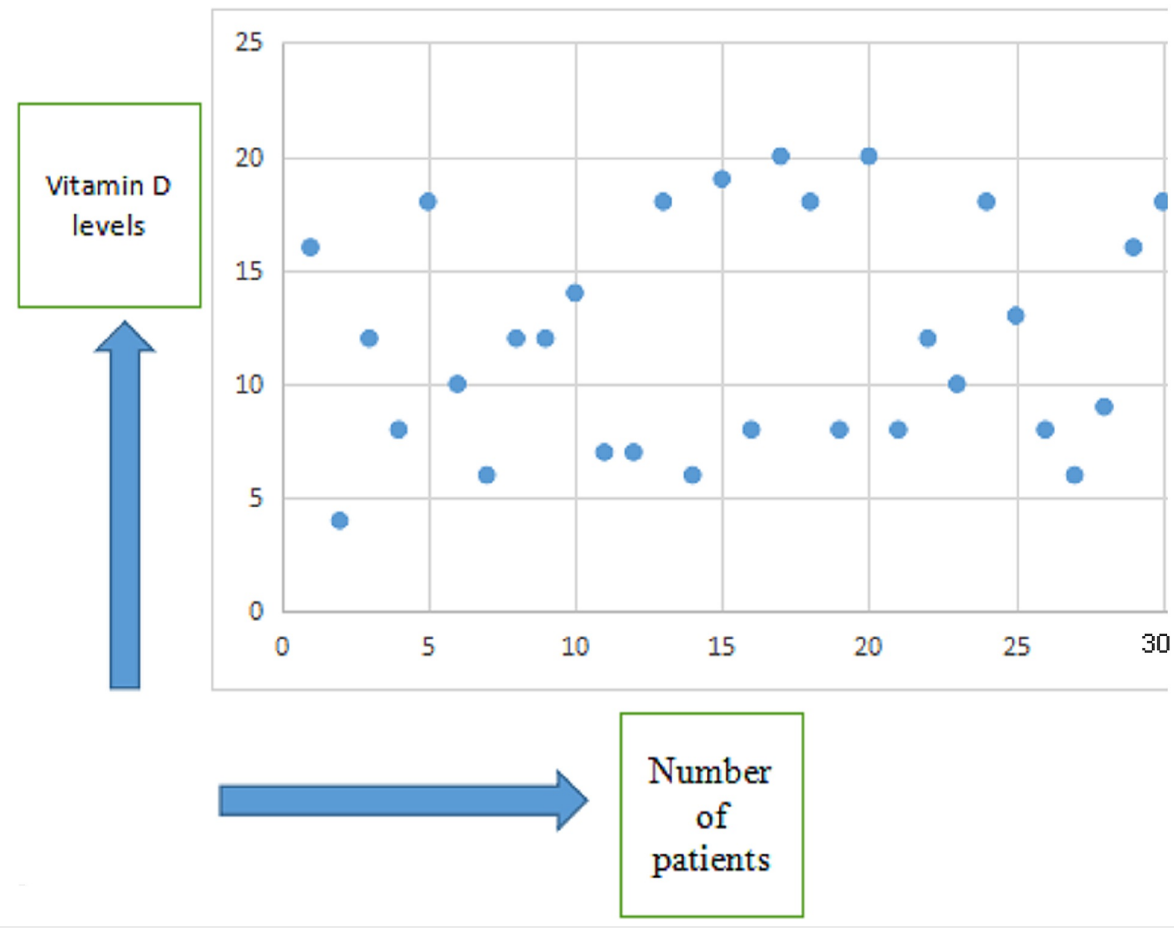

FIGURE 1: Scatter plot showing vitamin D levels in our study population

\section{Discussion}

Osteoporosis-induced fractures occur in one-third of females and one-quarter of males over 50 years of age. Globally, nearly nine million individuals with osteoporosis have a fracture per year [5]. Muscle fatigue, generalized body pain, decreased strength/balance, increased bone turnover, increased risk of falls, and sustenance of hip fractures are correlated with decreased serum levels of vitamin D in older adults [6]. Increased mortality was observed in patients with hip fractures and high mortality rates were observed in 
men relative to women. Higher mortality is correlated with institutionalization combined with co-morbidity [7]. The risk of hip and any non-vertebral fractures in outpatient or institutionalized elderly people tends to be minimized by sufficient levels of cholecalciferol or ergocalciferol (700-800 IU/day) [8]. In order to maximize potential benefits and mitigate potential risks, supplementation of vitamin D to restore $25(\mathrm{OH}) \mathrm{D}$ levels within a range of $30-50 \mathrm{ng} / \mathrm{ml}$ is appropriate. This, of course, should be taken into account in the sense of the patient's individual needs and co-morbidities [9] and the potential association between decreased mortality and post-fracture use of prescribed supplementation of calcium plus vitamin D and concomitant use of anti-osteoporotic drugs in females. Further investigations are required, however, in order to understand the reasons behind the reduction in the risk of death [10]. The prevalence of hypovitaminosis D in osteoporotic hip fracture patients is high and secondary hyperparathyroidism is observed in more than half of the cases. In patients with low sunlight exposure and low nutritional and functional status, vitamin D deficiency is particularly prevalent [11]. About three-quarters of patients with hip fractures have vitamin D deficiency and two-thirds have secondary hyperparathyroidism. The $25-\mathrm{OH}$ serum level can therefore be a useful index for assessing the risk of hip fracture in India [12]. The 25(OH) D insufficiency over five years was associated with an increased 10-year risk of hip and major osteoporotic fractures in these elderly women [13].

Taken together, our evidence shows that in the etiology of femoral neck fractures, impaired bone mineralization accompanied by low serum 25-(OH) D levels is of significant importance. Consequently balancing serum 25-OH D levels and thus normalizing serum PTH levels may counteract pronounced defects in mineralization and can reduce the incidence of femoral neck fractures [14]. After a fragility fracture, osteoporosis is diagnosed and treated with specific osteoporosis drugs in compliance with the guidelines and, if possible, does not impair the concept of fracture recovery; it substantially decreases the likelihood of future fractures. In order to improve fracture healing, further investigations are needed for approval [15]. In this systematic review and meta-analysis, no decreased risk of fracture was associated with either sporadic or regular dosing with standard doses of vitamin $\mathrm{D}$ alone, but a more promising approach was daily supplementation of both vitamin D and calcium [16].

An independent indicator of post-fracture mortality risk in both women and men was a rapid bone loss. The correlation between bone loss and post-fracture mortality was primarily observed in women and men following vertebral fracture and non-hip non-vertebral fracture in women. Whether the bone loss is a marker or plays a role in fracture-related mortality remains to be determined [17]. Non-vertebral fractures have recently been related to the risk of mortality. To better understand which particular fractures and variables contribute to the risk of fractures-associated mortality, larger studies are required. Due to its possible reversibility with anti-fracture therapies, the role of bone in post-fracture mortality needs to be confirmed in more studies [18]. Bisphosphonate and non-bisphosphonate osteoporosis drugs were significantly associated with reduced hip fracture mortality after fragility [19]. Monitoring serum concentrations of 25-hydroxyvitamin D annually can help reveal deficiencies in vitamin D. Responsive exposure to sunlight (usually five-ten minutes of exposure to the arms and legs or hands, arms, and face, two or more three days a week) and increased dietary and supplementary intakes of vitamin D are fairways of ensuring adequate vitamin D [20].

\section{Limitations of the study}

The key drawback of our research was the limited sample size and the single center. The present research did not have a control group. In order to further evaluate vitamin D levels and their association with osteoporosis and fracture site comminution in osteoporotic hip fractures, larger randomized controlled trials are needed.

\section{Conclusions}

As part of an overall strategy to improve bone health and to prevent or treat osteoporosis, older women and men should consult their healthcare providers about their nutrient requirements. Recommended levels of vitamin D from foods and supplements should be consumed.

Early diagnosis and treatment of these patients with vitamin D for osteomalacia and anti-osteoporotic osteoporosis regimens will hopefully enhance bone, muscle, and general health, minimizing falls and fractures.

\section{Additional Information}

\section{Disclosures}

Human subjects: Consent was obtained or waived by all participants in this study. Institutional Ethics committee , Sri Devaraj Urs Medical College, Kolar issued approval SDUMC/KLR/IEC/303/2019-20. Animal subjects: All authors have confirmed that this study did not involve animal subjects or tissue. Conflicts of interest: In compliance with the ICMJE uniform disclosure form, all authors declare the following: Payment/services info: All authors have declared that no financial support was received from any organization for the submitted work. Financial relationships: All authors have declared that they have no financial relationships at present or within the previous three years with any organizations that might have 
an interest in the submitted work. Other relationships: All authors have declared that there are no other relationships or activities that could appear to have influenced the submitted work.

\section{References}

1. American Geriatrics Society Workgroup on Vitamin D Supplementation for Older Adults: Recommendations abstracted from the American Geriatrics Society Consensus Statement on vitamin D for prevention of falls and their consequences. J Am Geriatr Soc. 2014, 62:147-52. 10.1111/jgs.12631

2. Holick MF, Binkley NC, Bischoff-Ferrari HA, et al.: Evaluation, treatment, and prevention of vitamin D deficiency: an Endocrine Society clinical practice guideline. J Clin Endocrinol Metab. 2011, 96:1911-30. 10.1210/jc.2011-0385

3. Ritu G, Gupta A: Vitamin D deficiency in India: prevalence, causalities and interventions . Nutrients. 2014, 21:729-75. 10.3390/nu6020729

4. Ensrud KE, Crandall CJ: Osteoporosis. Ann Intern Med. 2017, 167:ITC17-32. 10.7326/AITC201708010

5. Johnell O, Kanis JA: An estimate of the worldwide prevalence and disability associated with osteoporotic fractures. Osteoporos Int. 2006, 17:1726-33. 10.1007/s00198-006-0172-4

6. Visweswaran RK, Lekha H: Extraskeletal effects and manifestations of Vitamin D deficiency . Indian J Endocrinol Metab. 2013, 17:602-10. 10.4103/2230-8210.113750

7. Guzon-Illescas O, Perez Fernandez E, Crespí Villarias N, et al.: Mortality after osteoporotic hip fracture: incidence, trends, and associated factors. J Orthop Surg Res. 2019, 14:203. 10.1186/s13018-019-1226-6

8. Bischoff-Ferrari HA, Willett WC, Wong JB, Giovannucci E, Dietrich T, Dawson-Hughes B: Fracture prevention with vitamin D supplementation: a meta-analysis of randomized controlled trials. JAMA. 2005, 11:2257-64. 10.1001/jama.293.18.2257

9. Quraishi SA, Camargo CA Jr: Vitamin D and major chronic illness. J Restor Med. 2012, 1:9-23. 10.14200/jrm.2012.1.1001

10. Nurmi-Lüthje I, Lüthje P, Kaukonen JP, Kataja M, Kuurne S, Naboulsi H, Karjalainen K: Post-fracture prescribed calcium and vitamin D supplements alone or, in females, with concomitant anti-osteoporotic drugs is associated with lower mortality in elderly hip fracture patients: a prospective analysis. Drugs Aging. 2009, 26:409-21. 10.2165/00002512-200926050-00005

11. Larrosa M, Casado E, Gómez A, Moreno M, Berlanga E, Ramón J, Gratacós J: Déficit de vitamina D en la fractura osteoporótica de cadera y factores asociados [Vitamin D deficiency and related factors in patients with osteoporotic hip fracture]. Med Clin (Barc). 2008, 130:6-9. 10.1157/13114538

12. Dhanwal DK, Sahoo S, Gautam VK, Saha R: Hip fracture patients in India have vitamin D deficiency and secondary hyperparathyroidism. Osteoporos Int. 2013, 24:553-7. 10.1007/s00198-012-1993-y

13. Buchebner D, McGuigan F, Gerdhem P, Malm J, Ridderstråle M, Akesson K: Vitamin D insufficiency over 5 years is associated with increased fracture risk-an observational cohort study of elderly women. Osteoporos Int. 2014, 25:2767-75. 10.1007/s00198-014-2823-1

14. Seitz S, Koehne T, Ries C, et al.: Impaired bone mineralization accompanied by low vitamin D and secondary hyperparathyroidism in patients with femoral neck fracture. Osteoporos Int. 2013, 24:641-9. 10.1007/s00198-012-2011-0

15. Hesse E, Neuerburg C, Kammerlander C, Stumpf U, Stange R, Böcker W: Einfluss spezifischer osteoporosemedikamente auf die Frakturheilung [influence of specific osteoporosis drugs on fracture healing]. Unfallchirurg. 2019, 122:506-11. 10.1007/s00113-019-0669-X

16. Yao P, Bennett D, Mafham M, Lin X, Chen Z, Armitage J, Clarke R: Vitamin D and calcium for the prevention of fracture: a systematic review and meta-analysis. JAMA Netw Open. 2019, 2:1917789. 10.1001/jamanetworkopen.2019.17789

17. Bliuc D, Nguyen ND, Alarkawi D, Nguyen TV, Eisman JA, Center JR: Accelerated bone loss and increased post-fracture mortality in elderly women and men. Osteoporos Int. 2015, 26:1331-9. 10.1007/s00198-0143014-9

18. Bliuc D, Center JR: Determinants of mortality risk following osteoporotic fractures . Curr Opin Rheumatol. 2016, 28:413-9. 10.1097/BOR.0000000000000300

19. Wang PW, Li YZ, Zhuang HF, et al.: Anti-osteoporosis medications associated with decreased mortality after hip fracture. Orthop Surg. 2019, 11:777-83. 10.1111/os.12517

20. Holick MF: Sunlight and vitamin D for bone health and prevention of autoimmune diseases, cancers, and cardiovascular disease. Am J Clin Nutr. 2004, 80:1678-88. 10.1093/ajcn/80.6.1678s 